\title{
Acrofacial dysostosis, Weyers type
}

INSERM

\section{Source}

INSERM. (1999). Orphanet: an online rare disease and orphan drug data base. Acrofacial dysostosis, Weyers type. ORPHA:952

Acrofacialdysostosis, Weyers type (WAD) is a rare ectodermal dysplasia syndrome with bone abnormalities characterized by onychodystrophy; anomalies of the lower jaw, oral vestibule and dentition; post-axialpolydactyly; moderately restricted growth with short limbs; and normal intelligence. Although it closely resembles Ellis-van Creveld syndrome (see this term), an allelic disorder and another type of ciliopathy, WAD is usually a milder disease without the presence of heart abnormalities and is inherited in an autosomal dominant manner. 